Syntax Literate : Jurnal Ilmiah Indonesia p-ISSN: 2541-0849

e-ISSN: 2548-1398

Vol. 5, No. 5 Mei 2020

\title{
ANALISIS MINAT MAHASISWA MEMASUKI PROGRAM STUDI TEKNIK DENGAN MENGGUNAKAN METODE K-MEANS CLUSTERING DI POLITEKNIK HARAPAN BERSAMA
}

\section{Muchamad Sobri Sungkar}

Program Studi Teknik Elektronika Politeknik Harapan Bersama

Email: sobrisungkar@gmail.com

\begin{abstract}
The goal in study that analyzed student interest entered of engineering study program at the Harapan Bersama (Harber) Polytechnic. The method used is $K$ means clustering with study of literature and design earlier, start from concept, searching data until inputing and proccessing data who have entered. So the result is got namely in 2015 until 2019 interest of student to enter engineering study program is diverse.
\end{abstract}

Keywords: interest, study program, K-means clustering

\begin{abstract}
Abstrak
Tujuan dilakukannya penelitian ini yaitu untuk menganalisa suatu peminatan mahasiswa masuk program studi teknik di Politeknik Harapan Bersama (Harber). Metode yang digunakan adalah $K$-means clustering dengan studi literatur dan perancangan terlebih dahulu, mulai dari konsep, pencarian data hingga penginputan dan proses data yang sudah masuk. Sehingga hasil yang diperoleh yaitu dari tahun 2015 sampai dengan 2019 ini minat mahasiswa masuk program studi teknik beragam.
\end{abstract}

Kata kunci: minat, program studi, K-means clustering

\section{Pendahuluan}

"Program Studi berdasarkan UU no 12 tahun 2012 tentang Pendidikan dikatakan bahwa suatu kegiatan Pendidikan dan pembelajaran yang diajarkan dengan kurikulum dan suatu metod tertentu dalam satu jenis Pendidikan baik itu akademik, vokasi maupun Profesi , dilaksanakan pada Perguruan Tinggi maupun Lembaga Pendidikan.” (Kisworo, 2012).

Perguruan tinggi mempunyai fungsi yaitu meningkatkan kualaitas kinerja dan hasil pada sebuah perguruan tinggi, sehingga diharapakan mampu memberi kontribusi yang reel kepada IPOLEKSOSBUD pada masyarakat umum (Rahmat, 2014). Pembinaan kualitas dalam perguruan tinggi akan memadukan unit akademik dasar secara keseluruhan denganan adanya penilaian. Perangkat manajemen perguruan tinggi menggunakan evaluasi diri sewajarnya, dengan evaluasi diri inilah pengambilan keputusan akan ditentukan.

Maksud dari adanya evaluasi diri ini yaitu untuk malaksanakan rumusan secara prosedural terhadap baik di lingkungan dalam mapun luar, Prinsipnya untuk 
lingkungan dalam yang diintepretasikan dalam kelebihan dan kekurangan yang dihubungkan pada misi lembaga. Terkait dengan lingkungan luar dapat di kumpulkan berbagai informasi yang terkait dengan opportunity dan tantangan, tentunya tidak lepas dari misi Lembaga sebelumnya. (Basukiyatno, 2005).

Dalam dunia pendidikan penting untuk perguruan tinggi dalam menentukan program studi yang akan didirikan sesuai dengan minat masyarakat disekitar perguruan tinggi tersebut. "Peminatan adalah kemampuan yang cenderung meningkatkan focus pada hal tertentu. Peminatan merupakan factor penting yang berkesempatan mengerti tentang hal yang diminati serta dilakukan oleh masyarakat pada umumnya. Ketika salah satu orang memiliki peminatan, maka hal yang iya kerjakan mengarahkan pada peminatan itu.

Pendidikan tinggi di Indonesia sudah menyediakan berbagai program studi, salah satunya adalah di politeknik harapan bersama menyediakan berbagai program studi diantaranya DVI Teknik Informatika, DIII Teknik Komputer, DIII Teknik Elektronika, dan DIII Teknik Mesin

\section{Metode Penelitian}

Metode penelitian yang dilakukan berupa serangkaian perancangan dimana langkah-langkah yang akan dilakukan yaitu pertama, mencari data langsung melalui bagian akademik kampus. Pencarian data berupa wawancara dengan kepala bagian akademik Politeknik harapan bersama (Harber). Kedua pengumpulan data, Ketiga menganalisis variable yang di dapat serta melakukan sistem perancanganya, Keempat, melaksanakan uji variable pada sistem, Kelima menganalisa hasil akhir system.

Pada tahap tipe Analisa yang memeliki konten berupa diagram block yang terdiri dari preprocessing data, K-Means clustering. Di tahun 2015-2019 data nama prodi Teknik yang dirubah kedalam bentuk numerik untuk pengelompokan datanya menggunakan K-Means Algorithm Clustering. Agar semua data yang dimasukan dapat menjadi clsterter yang diperlukan dengan beberapa tahapan yang ada :

1. Menetukan cluster menjadi 3 bagian dari data yang diperoleh pada penelitian ini

2. Membuat titik utama pada cluster yang dibuat.

Penentuan titik utama dilakukan secara acak pada setiap cluster yang ditentukan dan diperoleh titik utama pada cluster yang diperoleh. nilai k didapat serta cluster utama awal setelah itu pengukuran jarak antara cluster utama digunakan euclidian distance, sehingga akan diketahui matrik jarak yaitu Cluster 1, Cluster 2 dan Cluster 3 sebagai berikut: 
Rumus euclidian distance:

$$
\mathrm{d}(\mathrm{x}, \mathrm{y})=|x-y|=\sqrt{\sum_{i=1}^{n}\left(x_{i}-y_{i}\right)^{2}}
$$

\section{Hasil dan Pembahasan}

\section{A. Hasil}

\section{K-Means Clustering}

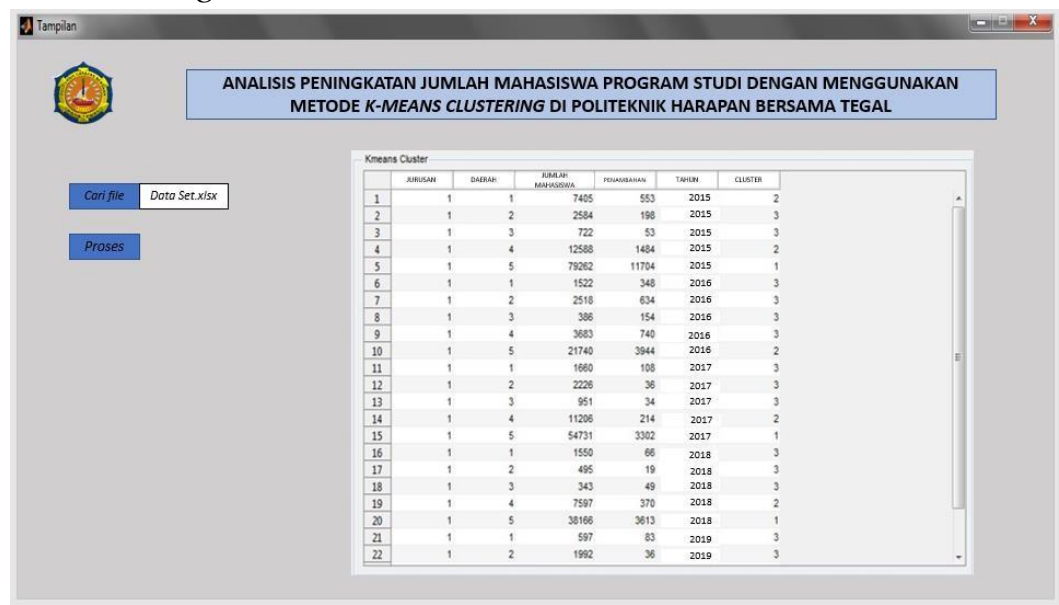

Gambar 1 Tiga cluster yang dibuat di K-Means

Pengunaan Metode K-Means clustering dalam mengelompokan data memakai 3 cluster dan kemudian diperoleh hasil yang tidak selaras atau mempunyai perbedaan total data yang rentangnya cukup jauh di setiap clusternya.

2. Input Data

Data sistem dijalankan, user akan melakukan langkah pertama yaitu input. Mencari file yang berektensi *.xlsx dengan cara menenekan button cari file yang akan digunakan, setelah file sudah ditemukan untuk dapat memprosesnya kita klik button prosess .

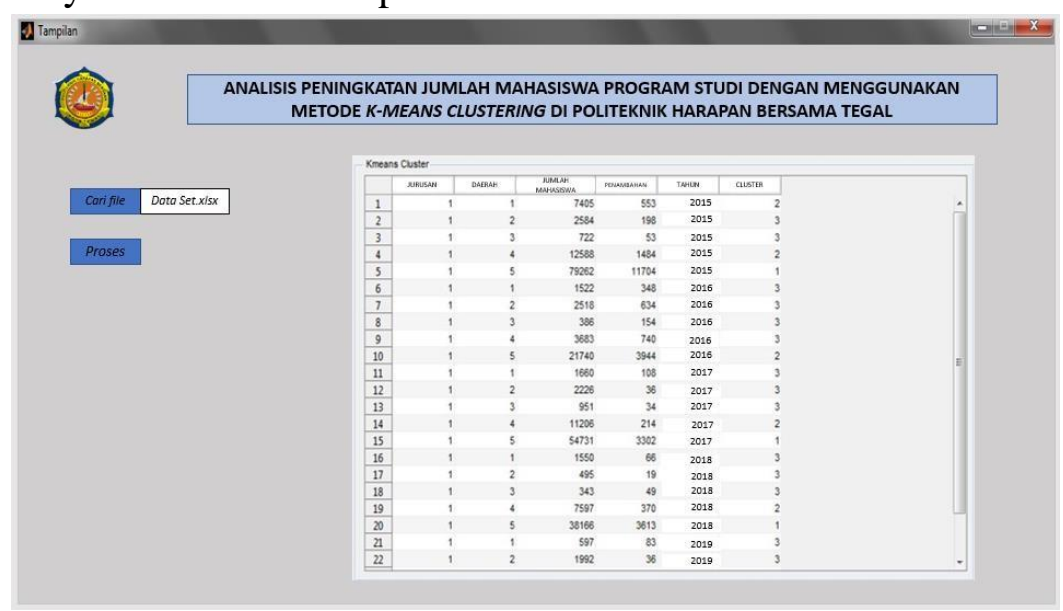

Gambar 2 Input Data 


\section{B. Pembahasan}

Attribute dalam pengelompokan ini adalah total mahasiswa yang minat Jurusan Teknik. Pengelolaan data digunakan K-Means clustering. Penelitian ini mempergunakan variable data dengan jumlah mahasiswa yang minat pada Jurusan Teknik di Politeknik Harapan Bersama.

\section{Teknik Komputer}

Minat mahasiswa masuk jurusan teknik komputer masuk pada grup minat yang dengan jumlah terbanyak pada 2015 hal ini terlihat dalam cluster ketiga adapaun 2016 - 2019 teknik komputer masuk dalam grup minat dengan jumlah sedang hal ini dapat terlihat di cluster kedua.

\section{Teknik Elektronika}

Minat mahasiswa masuk jurusan teknik elektonika, masuk pada grup minat dengan jumlah sedang pada 2015, 2016 serta 2019. hal ini terlihat dalam cluster kedua. Minat jurusan ini di 2017 serta 2018 masuk pada grup minat dengan jumlah sedikit.

3. Teknik Mesin

Teknik mesin pada tahun 2015,2016, dan 2018 masuk kedalam grup minat dalam jumlah terbanyak di cluster kesatu, di 2017 serta 2019 grup minat terbanyak berada di cluster kesatu.

4. Teknik Informatika

Teknik informatika termasuk dalam minat terbanyak di 2015 termasuk cluster kesatu. Jurusan ini masuk kedalam grup minat dengan jumlah sedikit di 2016 - 2019. Hal ini dapat dilihat di cluster ketiga.

\section{Kesimpulan}

Penelitian ini dilakukan di politeknik harapan bersama dengan objek yang diteliti adalah peminatan mahasiswa untuk kuliah pada program studi Teknik metode KMeans clustering. Sehingga hasil yang diperoleh bahwa dari tahun 2015 - 2019 minat mahasiswa tidak stabil. Untuk jurusan Teknik computer menyatakan bahwa pada tahun 2015 mahasiswa banyak yang berminat masuk jurusan tersebut. Hal serupa terjadi pada jurusan informatika yang pada tahun yang sama menyatakan banyaknya minat mahasiswa masuk jurusan informatika. Berbeda dengan jurusan elektronika yang menyatakan dari tahun 2015-2016 dan tahun 2018 mahasiswa yang minat masuk jurusan tersebut lebih sedikit/sedang. Berbeda pula dengan jurusan Teknik mesin dimana pada jurusan ini selalu mengalami kenaikan pada setiap tahunnya dan dikategorikan banyaknya minat mahasiswa terhadap jurusan Teknik mesin 


\section{BIBLIOGRAFI}

Kisworo, M. (2012). Undang-undang no. 12 tahun 2012 tentang Pendidikan Tinggi.

Prilianti, K. R., \& Wijaya, H. (2014). Aplikasi text mining untuk automasi penentuan tren topik skripsi dengan metode K-Means Clustering. Jurnal Cybermatika, 2(1).

Purnamaningsih, C. (2013). Pemanfaatan metode k-means clustering dalam penentuan penjurusan siswa sma.

Rahmawati, L., Sihwi, S. W., \& Suryani, E. (2016). Analisa Clustering Menggunakan Metode K-Means dan Hierarchical Clustering (Studi Kasus: Dokumen Skripsi Jurusan Kimia, Fmipa, Universitas Sebelas Maret). ITSMART: Jurnal Teknologi dan Informasi, 3(2), 66-73.

Rahmat, Agus Salam. "Model Pengembangan Pendidikan Nilai Di Perguruan Tinggi." (2014).

Suprawoto, T. (2016). Klasifikasi data mahasiswa menggunakan metode k-means untuk menunjang pemilihan strategi pemasaran. JIKO (Jurnal Informatika dan Komputer), 1(1).

Zaelani, Ahamad. "Pengaruh Kepribadian Wirausaha, Pengetahuan Kewirausahaan, dan Lingkungan terhadap Minat Berwirausaha Mahasswa/I Akademi Minyak Dan Gas Balongan Indramayu Jawa Barat." Syntax Literate; Jurnal Ilmiah Indonesia 2.10 (2017): 1-6. 